\title{
MUERTE, CONOCIMIENTO, MUERTE: LA POESÍA DE ANTONIO GAMONEDA
}

Túa BLESA

Universidad de Zaragoza

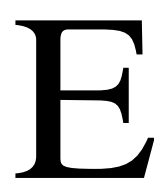

ntrar en la belleza de la palabra poética de Antonio Gamoneda una vez más y saber que no hay forma de franquear la entrada, que algo, quizá la belleza misma, la experiencia de ella como lector, impone su obstrucción a la lectura, al comentario. Saber eso antes de ponerse a escribir y, como por conjurar tal certeza, acudo a palabras del poeta: refiriéndose a uno de los muchos pasajes memorables de su obra, a ese en el que ya al final de Descripción de la mentira, dice «Este relato incomprensible es lo que queda de nosotros», precisaba en una entrevista que «lo de "incomprensible" es ciertamente para mí; donde trato de buscar la comprensión es en lo que digo, en lo que estoy diciendo: luego de decirlo, siempre llego a saber algo más» ${ }^{1}$. Se trata, pues, de decir, de escribir, para acceder por la palabra a un cierto saber que en el momento anterior estaba encerrado en el saber-sin-saber y al que de permanecer en el silencio no se pondrían las condiciones para aprehenderlo. La poesía de Gamoneda, entonces, es poesía del conocimiento, según se la viene denominando, modo que se enfrentaría al de la comunicación, los cuales dieron lugar a una polémica bien conocida en la poesía española contemporánea y a la que el propio Gamoneda no es ajeno; polémica que, por otra parte, estaba viciada, o solo contaminada si se prefiere, por el hecho de que en los años en que tuvo propiamente lugar la poesía, y la literatura española en general, conocía otro debate que, no siendo exactamente el mismo, resultaba, sin embargo, que se interferían y que era, claro está, lo referido a si lo literario debía, o no, ponerse al servicio de la cuestión política, estrictamente política, lo que hizo que el ideario de la poesía social no pudiera alejarse del de la poesía como comunicación, pues ¿a qué fin escribir en clave de denuncia, protesta, etc., si no se escribía para todos, es decir, aun para los menos instruidos?

Es el caso que, además de que la escritura poética de Gamoneda tiene las marcas que la identifican como tal, es autor de un ensayo titulado, muy significativamente, «Poesía y conocimiento. ¿Qué conocimiento?»².

\footnotetext{
${ }^{1}$ A. Gamoneda (2007), El lugar de la reunión. Conversaciones con Antonio Gamoneda, ed. Carmen Palomo, 213.

${ }^{2}$ A. Gamoneda (1997), El cuerpo de los símbolos, 31-36.
} 
Muerte, conocimiento, muerte: la poesía de Antonio Gamoneda

Pero antes aún de ese trabajo había sido escrito y publicado un libro que ha merecido escasa atención crítica, Sublevación inmóvil (1960), y bien se entiende ese poco eco por dos razones: una, la desaparición -la desaparición que dura a lo largo de «quinientas semanas»- del poeta Antonio Gamoneda hasta Descripción de la mentira (1977), forzada en parte por la resolución de la censura fascista sobre Blues castellano ${ }^{3}$, y la otra, el que en Descripción y en los libros posteriores la poesía gamonetaria es ya casi la de un poeta distinto. Sin embargo, ahí está Sublevación inmóvil y ya el título, con su contradicción desasosegante, exige algunas palabras. Vayamos al soneto que pone el cierre al volumen:
Ésta es la tierra, donde el sufrimiento es la medida de los hombres. Dan pena los condes con su fiel faisán y los cobardes con su fiel lamento.
La belleza nos sirve de tormento y la injusticia nos concede el pan. Un día brindaréis por los que habrán convertido el dolor en fundamento.
Los que vivimos para dar alcance a tan inmensa luz que hoy no podría un dios mirarla sin quedarse ciego,
aún tendremos que agotar el lance: arrojar al silencio la agonía como quien tira el corazón al fuego.

Palabra última del discurso de la sublevación, es bien distinta la temática de los cuartetos y la de los tercetos. En los primeros, se inserta el poema en la ya en aquel momento tópica denuncia -la tierra es el lugar del sufrimiento, los condes con su fiel faisán (extraña adjetivación, hay que decir; el faisán, por su parte, está sugerido, además de por la rima, quizá por la señal indirecta a la caza de la continuación) son símbolo de los poderosos, la migaja del pan es lo que la injusticia deja caer sobre los sometidos y desheredados, están además los cobardes que nada hacen por romper las reglas impuestas, etc.-; en los segundos, se pasa a hablar de la búsqueda de una «inmensa luz», de la que no se especifica de qué tipo de luz se trate, y se prevé lo que pueda ser el gesto final: callar la agonía de la vida, de esa vida perfilada en lo anterior, la que es regida por la injusticia, con una comparación que quizá sea el pasaje más poético del poema. Callar, la destrucción última, será como tirar el corazón al fuego. Así, estos versos llamarían a hablar, a actuar, a la no resignación, a la sublevación: poesía comprometida. En una entrevista lo expresa así el propio poeta: «Simplificando, te diré que mi primera etapa es una época de rebeldía, de aspiraciones, de deseo de justicia» ${ }^{4}$. Sin embargo, no deja de nombrarse la desesperanza, la «inmovilidad» en términos del léxico del libro, impuesta por la realidad

\footnotetext{
${ }^{3}$ Para lo relativo a los lamentables hechos en torno a Blues castellano, véase C. Palomo, Antonio Gamoneda. Límites (2007, 92-112), donde se reproduce el informe del censor, identificado como «don 29», en lo que es un escandaloso ejemplo de anonimato, típico de los sistemas fascistas, que encubre toda responsabilidad. Anonimato que, por desgracia, ciertas agencias siguen utilizando a fecha de hoy para encubrir a sus agentes.

${ }^{4}$ A. Gamoneda, El lugar de la reunión. Conversaciones con Antonio Gamoneda, op. cit., 19.
} 
brutal. Es el fracaso que se cierne sobre la acción: «Lo cierto es que yo [...] no puedo más que testificar un fracaso» ha dicho Gamoneda 5 .

Pero, como el lector habrá advertido, hay en los tercetos dos palabras, que se destacan en la rima -«lance», «alcance»-, que atraen a la lectura uno de los poemas de Juan de la Cruz en el que tales palabras se reiteran en varios momentos y, por supuesto, aunque no sólo, en final de verso, poema del que copio el inicio:

\footnotetext{
Tras de un amoroso lance, y no de esperanza falto, volé tan alto, tan alto, que le di a la caza alcance.
}

A la vista de esto, la «luz» que en el poema mismo está en principio por la justicia -la libertad, etc.- cobra otras significaciones. Y hay que tener en cuenta además que, según Gamoneda ha explicado, «En el libro Sublevación inmóvil hay una propuesta de identidad entre la justicia y la belleza. Debo decir que en aquella época juvenil la aspiración de la justicia era también la aspiración de la belleza» ${ }^{6}$; por otra parte, en uno de los exentos de ese ciclo se dice eso mismo: «la justicia de las cosas / es decir, / la poesía de las cosas» ${ }^{7}$. Entonces, la luz «que hoy no podría un dios mirarla sin quedarse ciego» no puede ser ya el atributo tradicional de lo divino, símbolo de dios o dios mismo, como, por ejemplo, lo es en la religión egipcia Ra, el disco solar, para los griegos Zeus va unido al rayo y en el cristianismo las aureolas doradas acompañan una extensísima iconografía.

El poema de Juan de Yepes es, como el conjunto de su obra, el relato de una búsqueda de la experiencia - «Tras de un amoroso lance, / volé tan alto, tan alto»-, de la experiencia, y de la experiencia misma -«le di a la caza alcance»- y hay que citar otros de sus versos:

$$
\begin{aligned}
& \text { Entréme donde no supe, } \\
& \text { y quedéme no sabiendo, } \\
& \text { toda sciencia trascendiendo. } \\
& \text { Yo no supe dónde entraba, pero, } \\
& \text { cuando allí me vi, } \\
& \text { sin saber dónde me estaba, } \\
& \text { grandes cosas entendí, } \\
& \text { que me quedé no sabiendo, } \\
& \text { toda sciencia trascendiendo. }
\end{aligned}
$$

Saber del que se sabe que no es sabido, que es Dios, experiencia mística aquí, se traslada a la escritura de Gamoneda despojado de la divinidad, de ahí que la luz, «inmensa luz» de la que habla el poema antes citado, cegara a un dios si la mirara. Con todo, saber sin Dios, y sin dios, que viene a ocupar el alto lugar de Dios, y de dios, de ahí que Gamoneda en sus versos haga suyas «alcance» y «lance». El propio poeta ha dicho al respecto cómo «En la juventud [la de Gamoneda] el nombre de

\footnotetext{
${ }^{5}$ Ibid., 22.

${ }^{6}$ Ibid., 45.

${ }^{7}$ A. Gamoneda (2004), Esta luz. Poesía reunida (1947-2004),89.
} 
Dios aparece usado en modo estético, como una metáfora de justicia, de fraternidad y de todo aquello que nos falta» ${ }^{8}$.

Esta luz es una presencia constante en la obra poética de Gamoneda y, por muy sabido que sea, hay que consignar que cuando llegó la ocasión de reunir su obra el título general que pasó a nombrarla fue Esta luz. Partiendo precisamente de «luz», propuse leer esta poesía en la tradición visionaria, la del «Apocalipsis»y Rimbaud ${ }^{9}$.

Pero, ciñendo ahora la lectura a la sección 3 de Sublevación inmóvil, la que cierra el soneto citado, hay que mencionar otros varios pasajes, de los cuales solo me referiré aquí a la cita que abre la sección: «Ir del signo a la cosa significada es profundizar en el mundo», tomada de André Malraux, como allí se señala, y es traducción de «Aller $\boldsymbol{d u}$ signe à la chose signifiée, c'est approfondir le monde». Quizá no sea innecesario recordar que Malraux, por su compromiso con la II República, su participación en la Guerra Civil con la escuadrilla «España», su novela L'espoir, la película Sierra de Teruel, era en el momento en que Gamoneda lo inscribe en su libro una clave que no necesitaba exégesis ninguna.

La frase en cuestión la pronuncia en La condition humaine ${ }^{10}$ el pintor japonés Kama-San en un diálogo con Clappique, en el que este, a través de un discípulo del pintor como traductor, interroga al artista por las razones que le mueven a pintar. Pero antes de decir nada sobre la mencionada expresión y con las precisiones de que la novela de Malraux se publicó en 1933 y hay traducción al español al menos desde 1936, y que la cita en Sublevación inmóvil se hace en esta lengua, convendrá prestar atención a dicho diálogo desde algo antes:

-Pourquoi peignez vous, Kama-San?

En kimono comme son disciple, un effet de lumière sur son crâne chauve, le vieux maître regardait Clappique avec curiosité.

Le disciple laissa le croquis, traduisit, répondit:

-Le maître dit: d'abord, pour ma femme, parce que je l'aime...

-Je ne dis pas pour qui, mais pour quoi?

-Le maître dit qu'il est difficile de vous expliquer. Il dit: «Quand je suis allé en Europe, j’ai vu les musées. Plus vos peintres font des pommes, et même des lignes qui ne représentent pas des choses, plus ils parlent d'eux. Pour moi, c'est le monde qui compte».

Kama dit une phrase de plus; à peine une expresión de douceur passa-t-elle sur son visage d'indulgente vieille dame.

-Le maître dit: «La peinture, chez nous, ce serait, chez vous, la charité». ${ }^{11}$

A la pregunta, pues, el artista, cuyo discurso ha incorporado parcialmente Gamoneda a su obra, apela en primer lugar a su mujer, cabe decir al amor, enseguida amplía la extensión de la causa, la etiología de su pintar: pinta por la gente -es así como se traduce «le monde»: «la gente»-, por todos los demás, por el otro, por caridad en el sentido del latín cāritas, digamos que por cariño a los otros,

\footnotetext{
${ }^{8}$ A. Gamoneda, El lugar de la reunión. Conversaciones con Antonio Gamoneda, op. cit., 45.

${ }^{9}$ T. Blesa (2008), «Sombras de luz», Ínsula, 17-18.

${ }^{10}$ Hasta donde sé, La condición humana, en traducción de César A. Cornet, la publicó en Buenos Aires Sur en 1936. Por lo menos desde 1952 se editó esa misma traducción en Buenos Aires por la Editorial Sudamericana, con numerosas reediciones. Tengo a la vista la traducción de Cornet editada por Planeta en Barcelona en 1989.

${ }^{11}$ A. Malraux (1989), Romans. Les Conquérants. La condition humaine. L'espoir, 319.
} 
en lo que es entonces un gesto puramente altruista, por otro y para el otro, y se podría y debería ahora hablar de humanismo, el humanismo del artista que da su obra como un don, lo que Leopoldo María Panero ha expresado como pocos en un haikú memorable de su Last river together: «Te ofrezco en mi mano / los sauces que no he visto» ${ }^{12}$. Es el arte, el texto poético, como don. Ahora bien, no habrá que dejar sin decir que dar, dar algo de lo propio, no es sino darse, darse a sí mismo en la cosa donada. Así, el don del poeta consiste en dar la palabra, dar su palabra, y en la palabra va, tan explícito como implícito, el saber, la emoción, todo un universo simbólico, que es el propio, y va en ello lo consciente y lo inconsciente, la palabra y su apertura a la interpretación, se ofrece él mismo en la mano al otro.

Hay que volver ahora a La condition humaine, pues en la continuación todavía se lee una razón más del pintar de Kama, ahora a pregunta de otro de los personajes, Gisors, y que, como se verá, es fundamental para lo que atañe a la poética de Gamoneda:

\footnotetext{
Un seconde disciple, cuisinier, aporta des bols de saké, puis se retira. Kama parla de nouveau. -Le maître dit que s'il peignait plus, il lui semblerait qu'il est devenu aveugle. Et plus qu'aveugle: seul.

-Minute! Dit le baron, un oeil ouvert, l'autre fermé, l'index pointé. Si un medecin vous disait: «Vous êtes atteint d'une maladie incurable, et vous mourrez dans trois mois», peindriez-vous encore?

-Le maître dit que s'il savait qu'il va mourir, il pense qu'il peindrait mieux, mais pas autrement.

-Pourquoi mieux? Demanda Gisors.

$[\ldots]$

Kama répondit. Gisors traduisit lui-même:

-Il dit: «Il y a deux sourires -celui de ma femme et celui de ma fille-dont je pensarais alors que je ne les verrais plus jamais, et j'aimerais davantage la tristesse. Le monde est comme les caracteres de notre écriture. Ce que le signe est à la fleur, la fleur elle-même, celle-ci (il montra l'un des lavis) l'est à quelque chose. Tout est signe. Aller du signe à la chose signifiée, c'est approfondir le monde, c'est aller vers Dieu. Il pensa que l'approche de la mort... Attendez...».

Il interrogea de nouveau Kama, reprit sa traduction: permettrait peut-être de mettre en toutes choses assez de ferveur, de tristesse, pour que toutes les formes qu'il peindrait devinssent des signes compréhensibles, pour que ce qu'elles signifient -ce que'elles cachent aussi- se révélat. ${ }^{13}$
}

Es decisivo en este pasaje el que se plantea la cuestión de la pintura -de la poesía- «en la perspectiva de la muerte». En otros lugares ${ }^{14}$ me he referido a esta posición poética, y vital, poniéndola en relación con una línea de pensamiento donde se encuentra con Martin Heidegger y Maurice Blanchot. Siendo lo característico del Dasein el proyectar, lo es el pro-yecto de la propia muerte: «La muerte es una posibilidad de ser de la que el Dasein mismo tiene que hacerse cargo cada vez. En la muerte, el Dasein mismo, en su poder-ser más propio, es inminente para sí» se lee en Ser y tiempo y un poco más adelante que «La angustia ante la muerte es angustia 'ante' el más propio, irrespectivo e insuperable poder-ser» ${ }^{15}$. Por su parte, Blanchot funde la muerte con la escritura y aun con la palabra, a la que nombra en «La littérature et le droit à la mort» como un «assassinat differé» ${ }^{16}$ y unas páginas después está el inolvidable «Quand nous parlons, nous nous appuyons à un tombeau» ${ }^{17}$, una lápida.

${ }^{12}$ L. M. Panero (2001), Poesía completa 1970-2000, ed. y pról. Túa Blesa, 216.

${ }^{13}$ A. Malraux, op. cit., 319-320.

${ }^{14}$ T. Blesa, «Sombras de luz», op. cit. y «Antonio Gamoneda: la poesía en la perspectiva de la muerte», en T. Blesa et alii (2009), Pensamiento literario español del siglo XX, 3 .

${ }^{15}$ M. Heidegger (2003), Ser y tiempo, trad., pról. y nn. Jorge Eduardo Rivera Cruchaga, 270-271.

${ }^{16}$ M. Blanchot (2001), «La littérature et le droit à la mort», La part du feu, 313.

${ }^{17}$ Ibid., 324. 
Es esta la línea de pensamiento en la que, a sabiendas o no, tiene su lugar el logos de Gamoneda, sin embargo, a la vista del texto de Malraux parece claro que fue ahí donde el poeta encontró la expresión de lo que, quizá, ya le pertenecía. O sin «quizá», pues en los textos que componen La tierra y los labios, los más antiguos que conocemos, se encuentran expresiones como «Yo te traeré las sombras / en el hueco de mis $\operatorname{manos} »^{18}$, «Acaso entre tu mirada / y mi voz los muertos vibran» ${ }^{19}$, «Atravesó el silencio [...] No nos dice qué llanto, qué palabra, qué viento; / en qué día, qué nieve, qué lejanas montañas, / ha cruzado a los muertos» ${ }^{20}$, «Únicamente porque muere, canta / mi palabra» ${ }^{21}$, «Es un hombre. Va solo por el campo. [...] Ya el hombre apenas llora. Se pregunta / por el sabor a muerto de su lengua ${ }^{22}$, «A la manera de los héroes, canto / una mezcla de muerte y alegría ${ }^{23} \mathrm{o}$ «Cabe / vida y muerte en mi voz» ${ }^{24}$. Es la palabra «muerte», es la muerte en la palabra, la palabra de la muerte, muerte o palabra, palabra en la perspectiva de la muerte.

En la perspectiva de la muerte, o incluso en la extrema proximidad del plazo de tres meses, Kama no solo continuaría pintando, sino que dice estar convencido de que lo haría mejor. La conciencia de la pérdida de las sonrisas - cómo no citar el título Arden las pérdidas-de las personas amadas le haría más agradable la tristeza y es entonces cuando el personaje, esa prefiguración del yo poético, cuando menos poético, «Gamoneda»-cuando menos poético: «[la muerte] No es un concepto, no es imaginación, es una vivencia» ${ }^{25}$, pronuncia la frase que el poeta insertaría en su escritura ${ }^{26}$. Gamoneda, al igual que Kama, se sitúa en la perspectiva de la muerte, lleva su trabajo a un nuevo nivel de profundidad, de conocimiento. Un conocimiento, el de la muerte, la muerte propia, que no se hace presente ni lo podría, que no está ahí sino por pro-yección, presente en cuanto por venir, y que, por tanto, no puede ser entendido sino como conocimiento por cuanto es aquello que aún no tiene lugar, por cuanto lo por venir es, y no puede ser de otro modo, conocimiento. Que aún no tiene lugar es como lo expresan estos versos ya citados de Juan de Yepes: «Entréme donde no supe, / y quedéme no sabiendo, / toda ciencia trascendiendo». No estará de más añadir ahora que el soneto de Sublevación inmóvil copiado más arriba, con su expresión de «dar alcance / a tan inmensa luz», como fórmula del conocimiento hacia el que se va, con la rima «alcance / lance», escrito necesariamente antes de 1960, ha de estar entre los primeros que vinculan la escritura de Juan de la Cruz, el trance místico al conocimiento. José Ángel Valente, por ejemplo, que insistió en tal propuesta, habría redactado su

\footnotetext{
18 A. Gamoneda, Esta luz. Poesía reunida, op. cit., 18.

${ }^{19}$ Ibid., 21.

${ }^{20}$ Ibid., 27.

${ }^{21}$ Ibid., 30.

22 Ibid., 31.

${ }^{23}$ Ibid., 34.

${ }^{24}$ Ibid., 35.

25 A. Gamoneda, El lugar de la reunión. Conversaciones con Antonio Gamoneda, op. cit., 29.

${ }^{26}$ Como se habrá observado, «approfondir le monde» se corresponde en Sublevación inmóvil con «profundizar en el mundo» (la cursiva es mía). En la traducción de Cornet citada se lee «profundizar el mundo». A. Malraux, op. cit., 142.
} 
«Conocimiento y comunicación»-donde hacia el final plantea el vínculo- en 1957, si bien ese importante ensayo no se publicó hasta $1963^{27}$, pero quede la cuestión para los historiadores.

Escribir para el otro como ejercicio de cāritas, según hemos visto que dice Kama del pintar, pero hay que matizar que ese escribir para el otro es también escribir para uno mismo, puesto que al ser lo escrito documento de conocimiento, puerta que se abre hacia este, el escritor al escribir, al poner en palabras eso que antes de hacerlo no se sabía, nuevo saber que hace del yo otro, otro yo, el que ya sabe. Y: «sólo sé lo que digo cuando ya está dicho» escribe Gamoneda en «Poesía y conocimiento» ${ }^{28}$ y en Descripción de la mentira, entre otros varios textos que deberían ser citados: «En mi saliva hay yodo y polución de alheña, pero mi lengua decolora sombras y enciende luces que no existían» ${ }^{29}$. Un conocimiento que en el caso de la poesía de Antonio Gamoneda habrá de leerse como inseparable de la perspectiva de la muerte. Dicho de un modo u otro, desapariciones, ausencia, pérdidas, etc.: ese es el conocimiento.

Valgan como apertura de la conclusión estas dos últimas anotaciones.

Se lee en La condition humaine: «Tout est signe» ${ }^{30}$; escribe Gamoneda: «todo es símbolo» ${ }^{31}$.

Se lee en La condition humaine: «signes comprensibles» ${ }^{32}$; escribe Gamoneda: «Este relato incomprensible es lo que queda de nosotros» ${ }^{33}$.

\section{Referencias bibliográficas}

BLANCHOT, Maurice, «La littérature et le droit à la mor»t, La part du feu, París, Gallimard, 2001 [19471948].

BLESA, Túa, «Sombras de luz», Ínsula, núm. 736 (abril de 2008).

— Tropelías, 2009, 19-40.

GAMOnedA, Antonio, El cuerpo de los símbolos, Madrid, Huerga y Fierro, 1997.

—_ Esta luz. Poesía reunida (1947-2004), Barcelona, Círculo de Lectores-Galaxia Gutenberg, 2004.

—_ El lugar de la reunión. Conversaciones con Antonio Gamoneda, ed. Carmen Palomo, Burgos, Dos Soles, 2007.

HeIDEGGER, Martín, Ser y tiempo, trad., pról. y nn. Jorge Eduardo Rivera Cruchaga, Madrid, Trotta, 2003.

MALraUX, André, Romans. Les Conquérants. La condition humaine. L'espoir, París, Gallimard, 1989.

\footnotetext{
${ }^{27}$ El texto ahora en J. Á. Valente (2008), Ensayos. Obras completas, II, ed. Andrés Sánchez Robayna, recop. e intr.. Claudio Rodríguez Fer, 39-46; sobre la fecha de la primera redacción, allí mismo, 1617.

${ }^{28}$ A. Gamoneda, El cuerpo de los símbolos, op. cit., 31.

${ }^{29}$ Id., Esta luz. Poesía reunida, op. cit., 187.

${ }^{30}$ A. Malraux, op. cit., 319.

${ }^{31}$ A. Gamoneda, El cuerpo de los símbolos, op. cit., 11.

${ }^{32}$ A. Malraux, op. cit., 320.

${ }^{33}$ A. Gamoneda, Esta luz. Poesía reunida, op. cit., 222.
} 
Tropelías. Revista de Teoría de la Literatura y Literatura Comparada, 21 (2014) 65

Muerte, conocimiento, muerte: la poesía de Antonio Gamoneda

Palomo García, Carmen, Antonio Gamoneda: límites, León, Publicaciones de la Universidad de León, 2007.

PANERo, Leopoldo María, Poesía completa 1970-2000, ed. y pról. Túa Blesa, Madrid, Visor, 2001.

VAlEnte, José Ángel, Ensayos. Obras completas, II, ed. Andrés Sánchez Robayna, recop. e intr.

Claudio Rodríguez Fer, Barcelona, Círculo de lectores-Galaxia Gutenberg, 2008. 